Revista de Dialectología y Tradiciones Populares, vol. LXX, n. ${ }^{\circ}$ 2, pp. 325-330, julio-diciembre 2015 ,

ISSN: 0034-7981, eISSN: 1988-8457,

doi: $10.3989 /$ rdtp.2015.02.001.07

\title{
Los centros de internamiento de extranjeros (CIEs) entre control migratorio y control social: una frontera interna y polimorfa
}

\author{
Immigration Detention Centres between Migratory \\ and Social Control: An Internal Polymorphic Border
}

\author{
Sabina Barone ${ }^{52}$ \\ Universidad Autónoma de Madrid
}

\section{RESUMEN}

Los CIEs son centros de reclusión de personas extranjeras sin documentos de residencia válidos o vigentes y este trabajo los piensa como parte del régimen fronterizo que hemos explorado aquí. Dentro del territorio europeo, con un oscurantista tratamiento de sus procedimientos y del respeto a los derechos humanos de los allí retenidos, los CIEs representan la constante amenaza de retención y expulsión de los extranjeros. Y no sólo sobre la población recién llegada al país, sino también sobre la ya residente, incluyendo a la población extranjera con arraigo. Se trata de "fronteras internas" que crean un sistema de control social polimorfo y provocan una sensación de miedo ante la potencial detención si se incurre en algún supuesto administrativo. Contra las retóricas de integración, los CIEs representan la constante amenaza de expulsión. Si bien los antropólogos no podrían haber accedido al interior de estos espacios de internamiento, la etnografía comprometida del voluntariado nos introduce a las historias de vida de los recluídos. Ello nos permite cuestionar la construcción de la noción de "migrante irregular" y de la agenda política alrededor de la lucha a la migración irregular y el control de los flujos para denunciar la problematicidad de los CIEs que manifiestan una escisión entre el planteamiento universalista de los DDHH y una aplicación injustamente restrictiva de los mismos.

Palabras clave: Fronteras polimorfas; Procesos migratorios; Centros de internamiento de extranjeros; Control social.

\footnotetext{
${ }^{52}$ Desde octubre de 2011 visita el CIE de Aluche, Madrid, como parte del programa de acompañamiento e incidencia política de la ONG Pueblos Unidos.
} 


\section{SUMMARY}

The Immigration Detention Centres (CIEs) operate on foreign immigrants lacking valid residence documents. Here, they are analyzed as part of the new border regime explored in this section. Located within European territory, managed with obscurantist procedures and disrespectful of the Human Rights of the people confined in them, they represent a constant threat of retention and expulsion of foreigners. And they do not just directly affect the newcomers, but also foreign residents, including already rooted immigrants. They are thus "internal borders" creatingin fact a polymorphic social control system, and provoking a widespread fear sensation towards a potential detention. Running against official integration rhetoric, CIEs represent the permanent threat of expulsión. If an anthropologist would have had trouble accessing these centres through standard ethnographic means, the committed ethnography of voluntary work allows the access to the experiences of those locked up there. Knowledge of the point of view of those migrants trapped in CIEs allows for the questioning of the very notion of "irregular immigrant" and the political agenda behind the fight against irregular immigration and the control of population flows. In this vein, the CIEs can be critiziced, as they can be understood as the result of a split in the universality of Human Rights, revealing anunfairly restrictive application of them.

Key words: Polymorphic Borders; Migratory Processes; Immigration Detention Centres; Social Control.

"Yo no be hecho nada malo, ¿por qué estoy aquí?. El desconcierto es el estado de ánimo que más frecuentemente se apodera de una persona recién detenida en un Centro de Internamiento de Extranjeros (CIE). La desorientación frente al cautiverio, el dolor por la repentina interrupción de la propia cotidianidad, la humillación causada por la dureza de las condiciones de reclusión... todo induce a pensar el aislamiento como un castigo frente a una no bien definida falta. La degradación que impone el internamiento se tiñe de culpabilidad y la persona necesita argumentar la propia inocencia, justificar que no se merece esta condena. No le brinda consuelo la respuesta de que el lugar donde se encuentra no es una cárcel y ni sus compañeros son reos: se trata de distinciones que no alivian la incertidumbre de su destino, ni la aspereza del encierro.

Los CIEs son centros de reclusión de personas extranjeras sin documentos de residencia válidos o vigentes y son un instrumento del sistema de control fronterizo. Éste se compone de una serie de medidas y procesos que complementan el control del perímetro geográfico del Estado. Hoy en día, la frontera no consiste exclusivamente en las vallas y en los trazados marítimos que señalan el límite físico de un país. La frontera se reproduce al interior del territorio en algunos "lugares liminales" de espera e inmovilización impuesta, como los CIEs y las "Salas de inadmisión" en los aeropuertos, a través de los cuales las autoridades valoran la posibilidad y/o llevan a cabo la expulsión de las personas no nacionales de la Unión Europea. Estos lugares remiten y posibilitan una variedad de procedimientos de control no sólo sobre la población recién llegada al país, sino además sobre la ya residente, afectando incluso a la población extranjera con arraigo. Se conforma así una regulación fronteriza de carácter total que ejerce un control social que defino como "polimorfa" por la variedad de las situaciones personales que sanciona y la pluralidad de los procedimientos administrativos que despliega.

La institución de los CIEs se inscribe en las políticas europeas orientadas a la gestión de los flujos migratorios. En España el primer centro de internamiento abre en 1985, 
mientras que en Francia se registra la práctica de detener a extranjeros desde 1975 (Le Courant 2010: 457), pero sin duda es la firma del Tratado Schengen la que los afianza como herramienta europea de gestión migratoria. Hoy por hoy se computan 285 establecimientos de retención forzosa (Global Detention Project) $)^{53}$. Su existencia supone una diferenciación entre ciudadanos nacionales y no nacionales de la Unión Europea que pone en entredicho la universalidad de los Derechos Humanos (Suárez-Navaz 2006). En Europa, el derecho a la libre circulación y a la libre elección de la residencia (Art. 13 de la Declaración Universal de los DDHH) son reconocidos exclusivamente a las y los nacionales de la Unión, mientras que son revocables para las y los extra-europeos quienes pueden encontrarse en la imposibilidad de obtener o de renovar el permiso de residencia. En este caso la persona se convierte en un "inmigrante irregular ${ }^{54} \mathrm{O}$ "ilegal", un estatus al cual se niegan de facto muchos DDHH, por ejemplo a la educación y a la atención sanitaria, como sucede a las personas internadas en los CIEs.

Quiero centrar mi reflexión en la diferencia entre la función que oficialmente se atribuye a los CIEs, garantizar la expulsión de extranjeros sin permiso de residencia válido, y las que desempeñan en práctica. Lo haré a partir del análisis de los diferentes perfiles de las personas detenidas que he venido conociendo en los últimos años. Esto me permite evidenciar: (a) la variedad de situaciones personales sancionadas a través de las órdenes de expulsión e internamiento, (b) el hecho de que el control social que se ejerce a través de los CIEs excede la mera función de control de los flujos migratorios, y (c) el carácter polimorfo de la frontera porque ya no es un límite territorial externo, sino una prohibición de residencia que se implementa a través de numerosos controles y restricciones.

Los CIEs operan como una frontera interna al territorio nacional que remite a la frontera externa de múltiples maneras. Para las personas interceptadas cruzando la valla o intentando entrar vía mar, los CIEs son lo único que ven de España y de Europa, una prolongación de esa frontera exterior que no han logrado superar, una puerta giratoria desde la cual se les devuelve a sus respectivos países ${ }^{55}$. Para quienes son retenidos en territorio peninsular, con una gran variedad de trayectorias migratorias y de integración a sus espaldas, los CIEs son el umbral de la frontera, una puerta de salida que borra su desarrollo personal hasta ese entonces y les devuelve a la condición de meros "extranjeros". El internamiento supone una interrupción forzosa de un proyecto personal, un tiempo de incertidumbre bajo la "amenaza de expulsión" (Le Courant 2010), un "no-lugar" reservado para individuos cuya residencia en España ya no es deseable, pero que todavía no se han ido.

Es el caso de N. de Nigeria, 23 años en España y con más de 17 años de cotizaciones pagadas y regulares contratos de trabajo. En 2011, en plena crisis económica española, pierde el trabajo, agota las prestaciones sociales y no puede renovar el permiso de residencia. Lleva consigo todos sus documentos, los informes de vida la-

\footnotetext{
53 Ver http://www.globaldetentionproject.org/home.html

${ }^{54}$ Uso el término "irregular" exclusivamente para reflejar su empleo por la Administración Pública, pero reconociendo su carácter problemático y arbitrario como una construcción políticolegal históricamente determinada.

55 Técnicamente en estos casos se adopta el término "devolución" en lugar de "expulsión", para enfatizar que las personas no tuvieron ninguna relación o arraigo en España.
} 
boral, los certificados de empadronamiento... Papeles bien ordenados para testimoniar una cotidianidad estable en España, que ahora se derrumba ante sus ojos. Su expulsión conllevará también la imposibilidad de disfrutar las cotizaciones que ha pagado a lo largo de los años. "Estoy padeciendo una gran injusticia" afirma impotente entre dolor y rabia. Es el caso de A. de Perú, llegado a España con ocho años y que descuidó solicitar la nacionalidad española al cumplir la mayoría edad. Como no consigue trabajo, tampoco obtiene la residencia y espera en el CIE que le envíen a un país con el cual está vinculado sólo por los datos anagráficos. Es el caso de A. de Senegal, 6 años en España, con un pequeño piso y un puesto fijo en el mercado de la plaza principal de una localidad turística menor de Andalucía y una red de contactos locales que le radican en el territorio, todo perdido al no recibir la renovación del permiso de residencia por tener ingresos juzgados insuficientes.

En todos estos casos el cruce de la frontera es un evento lejano que compone el pasado biográfico de personas afincadas en España y cuya expulsión no puede justificarse bajo la función del control de los flujos que se asigna a los CIEs. Como no son migrantes que entraron irregularmente en España, su situación se define como "irregularidad sobrevenida", tecnicismo que revela el carácter inquietantemente reversible de la integración social de las y los ciudadanos extranjeros. "Yo me sentía ya de aquí y pensé que era como vosotros..." comenta un interno del CIE. Parecería que el origen extranjero es una condición inalterable que en determinadas circunstancias vuelve a asechar a la persona poniendo en jaque su pertenencia plena en la sociedad donde se ha establecido.

Éste perfil de "extranjero arraigado" era el más difundido en el CIE de Madrid en los años 2011-2012. En ese entonces la estrategia defensiva de abogados y ONGs consistía en demostrar el arraigo, acreditable con relativa facilidad, lo cual dejaba un margen de maniobra para conseguir la revocación del internamiento y a veces de la expulsión. Esta realidad, comprobada visita tras visita, contradecía el discurso oficial que justificaba los CIEs como medida necesaria para contener los movimientos migratorios. Tal discrepancia era sorteada por el Ministerio de Interior con el argumento de que los extranjeros en los CIEs tenían antecedentes penales. Este razonamiento busca la legitimidad de los CIEs atribuyéndoles una nueva y problemática función de control social y reforzando el carácter punitivo de la expulsión. Se sugiere que las expulsiones y los CIEs sancionan la aceptabilidad no solo administrativa, sino también social de las personas extranjeras.

Aunque en ese momento la generalización del "perfil penal" de las y los internos no era corroborada por la realidad en los CIEs, se inaugura una línea argumentativa por la cual los perfiles de las y los extranjeros resultan esenciales para fundamentar la legitimidad de los CIEs y que, directa o indirectamente, genera nuevas prácticas de internamiento, orientándolas de manera selectiva. Desde 2013 aumenta significativamente el número de personas con antecedentes penales arrestadas a través de un procedimiento que ha seguido un mismo patrón: a la salida de la cárcel una vez cumplida la condena, la ilusión de libertad del ex-recluso encuentra una unidad de la Brigada de Extranjería que le traslada directamente al CIE. Se implementa así una lógica de "doble condena" por la cual para las y los no-europeos la pena asignada judicialmente no es suficiente para permitir su reincorporación social. Se anula su permiso de residencia, aunque siguiera vigente, y se llevan a cabo las expulsiones sin 
consideración de las circunstancias personales y familiares (como la presencia de hijos o padres en España) o de arraigo. En este nuevo escenario, que hace más difícil la posibilidad de recurrir, se corrobora la función de "limpieza social" de las expulsiones. Como una profecía auto-cumplida, la sanción del "perfil criminal" justifica y produce la imposible integración social de determinados grupos de personas y normaliza el internamiento para la conciencia personal y colectiva. Es revelador un comentario de pasillo intercambiado por algunos funcionarios en el CIE: "Ese nombre me sonaba y me di cuenta de que ya había estado acá, luego fue a la cárcel y ahora está de vuelta. Tarde o temprano todos acaban acá.... ${ }^{56}$.

Hay más perfiles de los cuales se alimenta la "maquinaria de la expulsión": los "perfiles étnicos", es decir personas cuyos rasgos fisionómicos las convierten en objetivo de redadas selectivas en las calles en correspondencia de los "vuelos macro" de deportación que se organizan desde los CIEs. Primero desmentidas y luego admitidas por la Policía Nacional, las "redadas étnicas" constituyen un procedimiento violatorio de los Derechos Humanos que no toma en cuenta las circunstancias personales y no otorga las garantías legales de defensa. El argumento de la optimización de los costes, generados por fletar vuelos ad $h o c$, es utilizado para legitimar estas prácticas que convierten los CIEs en "agujeros" que absorben sorpresiva y arbitrariamente a las y los extranjeros llevando a cabo expulsiones sin suficiente distinción.

Sin embargo, el internamiento es una medida ampliamente ineficaz para garantizar la expulsión. A falta de datos de 2014, en 2012 y 2013 más del 47\% de las personas internadas no llegaron a ser expulsadas (Pueblos Unidos 2015: 9). Esto se debe a una multiplicidad de dificultades prácticas y al cumplimiento de garantías legales que son de pleno conocimiento de las autoridades y que cuestionan no sólo la legalidad, sino la sensatez de dictar una detención que acaba siendo para muchas personas un inútil sufrimiento. La persistencia de un procedimiento tan infructuoso revela entonces otra intencionalidad latente de los CIEs: ser un castigo o una advertencia. En efecto, la precariedad y las duras condiciones ${ }^{57}$ vividas en el internamiento generan un "sentimiento de expulsabilidad" (Le Courant 2010: 462) que afecta a quienes pasan por los CIEs y quedan en el territorio nacional. Vuelven a la cotidianidad con el miedo a la expulsión y organizan su día a día a fin de evitar esa eventualidad. La frontera experimentada en el CIE es interiorizada como conciencia de la propia inseguridad.

Los CIEs son entonces fronteras internas que cumplen un rol de control social e introducen una disparidad entre las personas nacionales y las extranjeras que fractu-

\footnotetext{
${ }^{56}$ No obstante esta evolución de los discursos legitimadores de los CIEs, y de las razones de internamiento, se sigue deteniendo a personas sin ampararse en los criterios aportados oficialmente. En 2014, en Madrid, "el 28\% de las personas visitadas (...) estaba en el CIE por mera estancia irregular, sin tener ningún antecedente penal, ni siquiera un proceso penal pendiente" (Pueblos Unidos 2015: 22) y el 60\% había residido en España siete años o más (Pueblos Unidos 2015: 19), es decir cuenta con una posible trayectoria de arraigo.

57 Aunque se le defina como un "establecimiento público de carácter no penitenciario donde se retiene de manera cautelar y preventiva a extranjeros sometidos a expediente de expulsión" (BOE-A-1999-4528 y BOE-A-2014-2749), un CIE es gestionado por la policía a través de prácticas coercitivas (sustitución del nombre por un número, restricciones de la comunicación con el exterior, uso de esposas, cacheos de las habitaciones, salas de aislamiento, entre otras) improcedentes para un centro supuestamente no carcelario.
} 
ra la cohesión social y la universalidad de los derechos. Es fundamental cuestionar la construcción de la noción de "migrante irregular" y de la agenda política alrededor de la lucha a la migración irregular y el control de los flujos para denunciar la problematicidad de los CIEs que manifiestan una escisión entre el planteamiento universalista de los DDHH y una aplicación injustamente restrictiva de los mismos.

\section{BIBLIOGRAFIA CITADA}

Le Courant, Stefan. (2010) "L'interiorisation de la frontière sous menace d'expulsion. Le cotidien des étrangers en situation irrégulière", en Didier Fassin (dir.), Les nouvelles frontières de la société française: 455- 476. Paris: La Découverte.

Pueblos Unidos. 2015. CIE y expulsiones exprés. Madrid: Servicio Jesuita a Migrantes.

Suárez-Navaz, Liliana. 2006. "Ciudadanía e inmigración: ¿Un oxímoron?. Puntos de Vista 4: 29-47. 